\title{
Prevalence and correlates of low back pain among occupational therapy students in Northern Queensland
}

doi:10.2182/cjot.07.014. This paper was published in the CJOT Early Electronic Edition, Fall 2007.

Peter A. Leggat " Derek R. Smith $~=$ Michele J. Clark

\section{Key words}

- Students, occupational therapy = Musculoskeletal " Lower back pain " Risk factor

\section{Mots clés}

- Ergothérapie, étudiant - Musculo-squelettique | Lombalgie - Facteur de risque

\begin{abstract}
Background. Although low back pain (LBP) is an important issue for the health profession, few studies have examined LBP among occupational therapy students. Purpose. To investigate the prevalence and distribution of $L B P$, its adverse sequelae; and to identify potential risk factors. Methods. In 2005, a self-reported questionnaire was administered to occupational therapy students in Northern Queensland. Findings. The 12-month period-prevalence of LBP was 64.6\%. Nearly half (46.9\%) had experienced pain for over 2 days, $38.8 \%$ suffered $L B P$ that affected their daily lives, and $24.5 \%$ had sought medical treatment. The prevalence of $\angle B P$ ranged from 45.5 to $77.1 \%(p=0.004)$, while the prevalence of $\angle B P$ symptoms persisting longer than two days was 34.1 to $62.5 \%(p=0.020)$. Logistic regression analysis indicated that year of study and weekly computer usage were statistically-significant $L B P$ risk factors. Implications. The occupational therapy profession will need to further investigate the high prevalence of student LBP identified in this study.
\end{abstract}

\section{Résumé}

Description. Bien que la lombalgie soit un problème important pour les professions de la santé, peu d'études ont porté sur la lombalgie chez les étudiants en ergothérapie. But. Examiner la prévalence, la distribution et les séquelles de la lombalgie et déterminer les facteurs de risque possibles. Méthodologie. En 2005, des étudiants du nord des Queensland ont répondu à un questionnaire à remplir soi-même. Résultats. La période de prévalence de 12 mois de la lombalgie était de 64,6\%. Près de la moitié des étudiants (46,9\%) avaient éprouvé de la douleur pendant plus de deux jours, 38,8\% souffraient d'une douleur lombaire qui avait perturbé leur vie quotidienne et $24,5 \%$ avaient fait appel à des traitements médicaux. Les taux de prévalence de la lombalgie s'étendaient de $45,5 \%$ à $77,1 \%(p=0,004)$, alors que les taux de prévalence des symptômes de la lombalgie persistant plus de deux jours étaient de $34,1 \%$ à $62,5 \%(p=0,020)$. L'analyse de régression logistique a indiqué que l'année d'étude et l'usage hebdomadaire de l'ordinateur étaient des facteurs de risques associés à la lombalgie qui étaient significatifs au plan statistique. Conséquences. La profession d'ergothérapeute devra examiner davantage la prévalence élevée d'étudiants atteints de lombalgie qui a été mise en relief dans cette étude.

$\mathrm{L}$ ow back pain (LBP) is a major public health problem on a global scale. The lifetime prevalence of this condition ranges from $58 \%$ and $84 \%$ of the general population (Woolf \& Pfleger, 2003). In the workplace, it is one of the most common occupational health problems, comprising around $22 \%$ of workers' compensation claims annually in Australia alone (National Occupational Health and Safety Commission [NOHSC], 2002). Previous research suggests that health professionals are particularly prone to LBP, with high 12-month period prevalence rates documented among nurses (74\%) (Smith, Leggat, Smyth, \& Wang, 2003) and dentists (53\%) (Leggat \& Smith, 2006). Students of the health professions have also reported high LBP prevalence rates in various international studies. In a Swedish investigation, for example, first-year occupational therapy students experienced similar prevalence rates of LBP during the previous 12 months as nursing students, with the condition affecting more than $40 \%$ of people in each student group (Kamwendo, 2000). In Australian studies, high 12 month period prevalence rates for LBP have also been documented among medical students (Smith \& Leggat, 2007) and nursing students (59\%) (Smith \& Leggat, 2004) in North Queensland. These rates represent a major concern as health science students will soon be entering professions in which they will be under- 
taking tasks that are not only potentially physically demanding, but tasks that could increase their risk of occupational LBP. In occupational therapy, the physical demands may be considerable, particularly with activities associated with the rehabilitation of people with disabilities.

In Australia, there are currently about 12,000 occupational therapists, and, in 2004, there were about 2,472 undergraduate occupational therapy students, although figures suggest that it is a growing profession (Occupational Therapy Australia, 2005). Few studies have examined the health of occupational therapy students in general, and very little is known about LBP among occupational therapy students or the impact of LBP on the work of occupational therapists. This dearth of information was the impetus for a detailed epidemiological investigation of LBP that was conducted among Australian occupational therapy students. A self-report survey was used, which is a methodology considered to be a cost-effective strategy for collecting epidemiological data on musculoskeletal disorders (MSD) among large groups. Furthermore, the validity and accuracy of this kind of assessment tool has been demonstrated in a number of studies in many countries, such as China, Sweden and the United States (Baron, Hales, \& Hurrell, 1996; Björkstén, Boquist, Talbäck, \& Edling, 1999; Holmström \& Moritz, 1991; Smith, Wei, Zhao, \& Wang, 2004). The usefulness and convenience of MSD questionnaires has also been demonstrated in studies of university students at an international level (Hamilton, Jacobs, \& Orsmond, 2005; Hupert et al., 2004; Rising, Bennett, Hursh, \& Plesh, 2005; Smith et al., 2005; Smith \& Leggat, 2004; Smith, Sato, Miyajima, Mizutani \& Yamagata, 2003). The aim of this study, therefore, was to investigate the prevalence and related sequelae of LBP among Australian occupational therapy students as well as helping to identify potential risk factors for the condition.

\section{Methods \\ Participants}

All undergraduate occupational therapy students currently enrolled in a four-year program at a large regional university in northern Queensland, Australia and who were on-campus were recruited for this study. Third-year students were not available as they were off-campus completing required practical training. Of those students currently on-campus, 46,55 , and 49 of them were available from the first, second, and fourth years of the program, respectively. All were considered eligible and were approached to participate in this study.

\section{Data collection}

\section{Administration of the questionnaire}

The study protocol was reviewed and approved by the James Cook University Human Research Ethics Committee in 2005. The research design and methodology followed ethical stan- dards appropriate for human research in Australia. Epidemiological data on occupational therapy students' LBP was gathered by means of an anonymous, self-reporting questionnaire. In 2005, questionnaires were distributed at the end of a lecture period for each year of the occupational therapy course under investigation. The researchers introduced the purpose of the study briefly but carefully while the questionnaires were being distributed. There were no penalties or rewards for participation, and informed consent was implied if students completed and returned their questionnaires. Information sheets about the study, which the students could retain, were distributed with the questionnaire.

\section{Questionnaire design}

The survey itself was a concise two-page A4 form, based predominately on the Standardised Nordic Questionnaire for the Analysis of Musculoskeletal Symptoms (Kuorinka et al., 1987) supplemented with questions used in other LBP investigations conducted among university students in various countries (Hamilton et al., 2005; Hupert et al., 2004; Rising et al., 2005; Smith et al., 2005; Smith \& Leggat, 2004; Smith, Sato, et al., 2003). It comprised a simple check-box format, with the first section covering demographic items such as age, sex, year of study in the occupational therapy course, the type of exercise they usually undertook (if any), and the presence of a family history of injuries (arthritis, slipped discs, ligament damage, or carpal tunnel syndrome). Two additional questions included a five-point scale ( $<6$ hours, 6-10 hours, 11-15 hours, 16-20 hours, and $>20$ hours) to establish the usual amount of time spent on a computer every week and the amount of time spent doing desk work per week (independent of the computer).

A simple anatomical diagram aided the respondents in answering questions focusing on the occurrence of LBP symptoms during the previous 12 -month period. The term 'low back pain' referred to any ache, pain, or discomfort in the defined lower back region as originally described by Kuorinka et al. (1987). LBP may also be further defined as "pain localised below the line of the twelfth rib and above the inferior gluteal folds, with or without leg pain" (Woolf \& Pfleger, 2003, p. 652). The validity and reliability of the Nordic Questionnaire has previously been found to be acceptable (Baron et al., 1996). As such, this methodology was considered appropriate for a study of occupational therapy students. Clearly labelled arrows indicated shaded regions on the anatomical diagram corresponding to the appropriate body site for LBP. Additional questions asked about the duration of symptoms, whether they affected the student's daily life, and whether any treatment had been sought for the condition. A 12-month recall period was used throughout, as this has been shown in previous student investigations to be an appropriate timescale (Smith et al., 2005; Smith \& Leggat, 2004; Smith, Sato, et al., 2003). 


\section{Data analysis}

Data were entered into an Excel spreadsheet program and analysed using Statistical Package for the Social Sciences (Version 12.0, SPSS, 2005). Demographic items were stratified by year of study, and statistically significant differences between the years were evaluated using the chi square test (for discrete variables) and one-way analysis of variance (for continuous variables such as age and year of study). The prevalence rate for LBP was calculated, with statistically significant differences between the genders were evaluated using the chi square test (for variables with cell counts over five) and Fisher's Exact Test (for variables with cell counts five or under). Logistic regression analysis was also performed to elucidate possible correlations between LBP and various other factors (such as demographic items, sporting activity, computer usage, deskwork, and so on). Results were evaluated using odds ratio calculations, which are the ratio between the expected rate and the actual rate of the outcome of interest, in this case, LBP. A value of 1.0 therefore, indicates no increased or decreased risk (Bland \& Altman, 2000). All statistical analysis to identify LBP correlates was conducted simultaneously in a combined regression model, which included age, sex, year of study, alcohol consumption, tobacco consumption, parenthood, status, usual weekly exercise levels, computer usage and the presence of a family history of musculoskeletal injuries. All output from statistical analysis was subsequently expressed as adjusted odds ratios (OR) with 95\% confidence intervals (95\% CI). Probability values below 0.05 were regarded as statistically significant for all tests.

\section{Results \\ Demographic items}

Completed questionnaires were received from 44, first-year occupational therapy students, 55 second-year students, and 48 fourth-year students. The response rates were $95.7 \%$,

TABLE 1

Demographic distribution of occupational therapy students

\begin{tabular}{|c|c|c|c|c|}
\hline & First year $^{\mathrm{a}}$ & Second year ${ }^{a}$ & Fourth year ${ }^{a}$ & Total \\
\hline \multicolumn{5}{|l|}{ Gender } \\
\hline Female n (\%) & $36(81.8)$ & $49(89.1)$ & 43 (89.6) & \\
\hline Male n (\%) & $8(18.2)$ & $6(10.9)$ & $5(10.4)$ & \\
\hline Age Groups & n $\quad(\%)$ & $\mathrm{n} \quad(\%)$ & n $\quad(\%)$ & $\mathrm{n}$ \\
\hline Under 20 years & $31(47.7)$ & $34(52.3)$ & $\begin{array}{ll}0 & (0.0)\end{array}$ & 65 \\
\hline 20-24 years & 7 (10.9) & $13(20.3)$ & $44(68.8)$ & 64 \\
\hline $25-29$ & $4(40.0)$ & $3(30.0)$ & $3(30.0)$ & 10 \\
\hline $30-34$ & $1(20.0)$ & $4(80.0)$ & $0 \quad(0.0)$ & 5 \\
\hline $35-39$ & $1(50.0)$ & $\begin{array}{ll}0 & (0.0)\end{array}$ & $1(50.0)$ & 2 \\
\hline 40 and over & $\begin{array}{ll}0 & (0.0)\end{array}$ & $1(100.0)$ & $0 \quad(0.0)$ & 1 \\
\hline Mean Age (SD) ${ }^{b}$ & $20.0(4.1)$ & 21.0 & $22.0(2.6)$ & \\
\hline
\end{tabular}

${ }^{a}$ Number of students in each year ( $n=44,55$, and 48 , respectively)

${ }^{\mathrm{b}}$ Mean ages not significantly different between years $(\mathrm{P}$ for Trend $=0.0614$ )
TABLE 2

Prevalence (\%) of low back pain among occupational therapy students by gender

\begin{tabular}{lrrrrrrr}
\hline & \multicolumn{2}{c}{ Male } & \multicolumn{2}{c}{ Female } & \multicolumn{2}{c}{ All } \\
& $\mathrm{n}$ & $(\%)^{\mathrm{a}}$ & $\mathrm{n}$ & $(\%)^{\mathrm{b}}$ & $\mathrm{n}$ & $(\%)^{\mathrm{c}}$ \\
\hline Any Symptoms & 10 & $(52.6)$ & 85 & $(66.4)$ & 95 & $(64.6)$ \\
Persisted >2 Days & 9 & $(47.4)$ & 60 & $(46.9)$ & 69 & $(46.9)$ \\
Affected Daily Life & 6 & $(31.6)$ & 51 & $(39.8)$ & 57 & $(38.8)$ \\
Needed Treatment & 3 & $(15.8)$ & 33 & $(25.8)$ & 36 & $(24.5)$ \\
\hline
\end{tabular}

${ }^{a} \mathrm{n}=19,{ }^{\mathrm{b}} \mathrm{n}=128,{ }^{\mathrm{c}} \mathrm{N}=147$

$100 \%$, and $97.7 \%$, respectively. These demographic characteristics have been summarised in Table 1.

\section{Prevalence of LBP}

The 12-month period-prevalence of LBP was $64.6 \%$ and there were no significant associations with gender. LBP episodes persisted longer than 2 days in the past year for $46.9 \%$ of students. Thirty-eight point eight percent (38.8\%) suffered LBP that affected their daily life, while approximately one quarter $(24.5 \%)$ needed some type of treatment. None of these results showed statistically significant differences by gender (see Table 2). The distribution of LBP and its related sequelae, however, varied significantly by year of study in the occupational therapy course. The prevalence of reported LBP symptoms ranged from $45.5 \%$ to $77.1 \%$ ( $\mathrm{P}=$ 0.004), while the prevalence of reported LBP symptoms persisting over two days ranged from $34.1 \%$ to $62.5 \%$ ( $\mathrm{P}=$ 0.020 ), both increasing from first year to fourth year. LBP affecting their daily life ranged from $29.5 \%$ to $50.0 \%$, again increasing from first to fourth year, while the prevalence of LBP requiring treatment (among all students) ranged from $18.2 \%$ to $35.4 \%$ (see Figure 1 ).

\section{Statistical Correlations with LBP}

Logistic regression analysis indicated that year of study and weekly computer usage were statistically significant risk factors for LBP. Year of study in the occupational therapy course was another important correlate for LBP. In this regard, fourth-year students were around twice as likely to report LBP (OR 2.26, 95\% CI: 1.03 - 5.26) than students in the other grades. Computer usage also incurred a certain degree of risk, with students who spent 16-20 hours per week on the computer incurring an increased risk of LBP (OR 5.46, 95\% CI: 1.12 - 33.14) (see Table 3). Those occupational therapy students participating in team sports were more likely to seek medical treatment for LBP (OR 2.65, 95\% CI: 1.04-6.88) It was interesting that occupational therapy students participating in 6-10 hours per week of exercise appeared to incur LBP symptoms which persisted over two days (OR 0.43 , 95\% CI: 0.19-0.91), when compared to students who undertook $<6$ or $>10$ hours of exercise per week. No other statistically signifi- 
FIGURE 1

Prevalence (\%) of low back pain (LBP) by year of study.

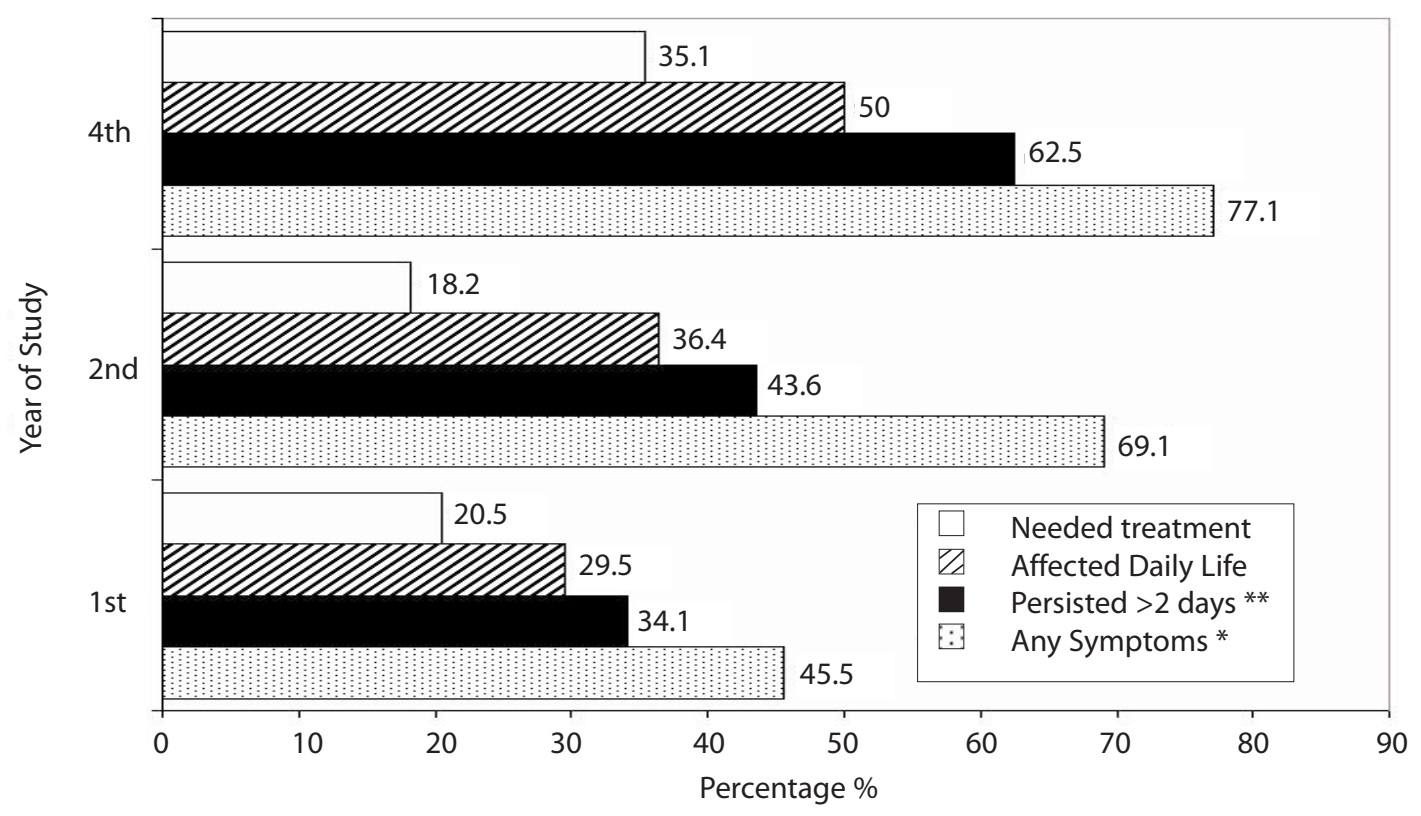

Note: Significant differences in prevalence rates between year of study in the occupational therapy course $(* \mathrm{P}$ for Trend $=0.004, * * \mathrm{P}$ for Trend $=0.020$ )

cant correlations with LBP were identified during logistic regression analysis.

\section{Discussion}

LBP appears to be a problem commonly suffered by occupational therapy students, affecting nearly two-thirds (64.6\%) of the group we surveyed. This result was higher than previous investigations of LBP conducted among nursing students in Korea (39.1\%) (Smith et al., 2005), Australia (59.2\%)
(Smith \& Leggat, 2004), and Japan (13.5\%) (Smith, Sato, et al., 2003). It was also higher than results reported among first-year Swedish physiotherapy students (38\%) (Kamwendo, 2000) and American dental students (18\%44\%) (Rising et al., 2005). However, the prevalence of LBP among first-year occupational therapy students in this study (45.5\%) was comparable with that reported by first-year Swedish occupational therapy students (46\%) (Kamwendo), the only year investigated. Previous investigations suggest

\section{TABLE 3}

Statistical correlations with low back pain (LBP) among occupational therapy students

\begin{tabular}{|c|c|c|c|c|c|c|c|}
\hline Outcome $^{a}$ & Correlate $^{\mathrm{b}}$ & Category $^{c}$ & $\mathrm{OR}^{\mathrm{d}}$ & $(95 \% \mathrm{Cl})$ & Std. Error & Estimate & P-value \\
\hline \multirow[t]{2}{*}{ LBP e } & Year of study & 1 st yr only & 0.30 & $(0.13-0.66)$ & 0.203 & -0.601 & 0.003 \\
\hline & & 2nd or 4th yr & 1.00 & - & - & - & - \\
\hline \multirow[t]{2}{*}{ LBP e } & Year of study & 4th yr only & 2.26 & $(1.03-5.26)$ & 0.207 & 0.408 & 0.049 \\
\hline & & $1 \mathrm{st}$ or $2 \mathrm{nd} \mathrm{yr}$ & 1.00 & - & - & - & - \\
\hline \multirow[t]{2}{*}{ LBP e } & Computer usage & $16-20$ hrs / wk & 5.46 & $(1.12-33.14)$ & 0.424 & 0.848 & 0.045 \\
\hline & & $<16$ or $>20$ hrs $/$ wk & 1.00 & - & - & - & - \\
\hline \multirow[t]{2}{*}{ LBP $>2$ days $^{f}$} & Regular exercise & $6-10 \mathrm{hrs} / \mathrm{wk}^{\mathrm{g}}$ & 0.43 & $(0.19-0.91)$ & 0.195 & -0.425 & 0.030 \\
\hline & & $<6$ or $>10 \mathrm{hrs} / \mathrm{wk}$ & 1.00 & - & - & - & - \\
\hline \multirow[t]{2}{*}{ LBP treatment ${ }^{\mathrm{h}}$} & Regular exercise & Team sports ${ }^{i}$ & 2.65 & $(1.04-6.88)$ & 0.239 & 0.486 & 0.042 \\
\hline & & Other sports & 1.00 & - & - & - & - \\
\hline
\end{tabular}

a Outcome of interest,

b Factor that incurred a statistically significant correlation with that outcome,

c Category or value of the correlating factor,

d Results from logistic regression expressed as adjusted odds ratios (OR) with 95\% confidence intervals ( $95 \%$ CI) (all values are adjusted for age, sex, alcohol consumption, tobacco consumption and parenthood status),

e Any LBP in the past 12 months,

f Any LBP episode that persisted longer than 2 days in the past 12 months,

$g$ Duration of regular exercise usually undertaken,

$\mathrm{h}$ Any LBP episode that required medical treatment in the past 12 months,

i Type of regular exercise usually undertaken 
that Australian occupational therapy students may suffer LBP at a rate similar to hospital nurses in the United States (47.0\%) (Trinkoff, Lipscomb, Geiger-Brown, \& Brady, 2002) and Sweden (56\%) (Lagerström, Wenemark, Hagberg, Hjelm, \& The Moses Study Group, 1995).

The relatively high prevalence of LBP amongst first-year occupational therapy students in this study is cause for concern. Similar to the findings of Kamwendo (2000), our results suggest that occupational therapy students may bring a certain level of LBP problems with them, rather than primarily acquiring them through professional exposure. Nevertheless, our study does suggest that the prevalence of LBP probably increases through the latter years of the occupational therapy course. Some previous studies of nursing students have suggested that this seemingly high baseline level of LBP may be due at least in part to professional exposure, such as previous hospital work experience (Kamwendo). Prior professional experience as well as continuing part-time work on the part of occupational therapy students may, therefore, comprise important factors to be examined in future studies.

It is difficult to explain differences in LBP prevalence rates between the occupational therapy students in our current study and those in other student investigations. Nevertheless, it has previously been suggested that inter-student differences in health-promoting behaviour may occur within universities of the same country. Najem, Passannante, and Foster (1995), for example, conducted a multi-faculty study at their university and found that medical students exercised more frequently than dental students or nursing students. Coe, Miller, Wolff, Prendergast, and Pepper (1982) documented that medical students undertook health-promoting behaviour more regularly than law students at the same university. Kamwendo (2000) also showed that Swedish occupational therapy students were more physically active and smoked less than nursing students. It is possible that differences in health-promoting behaviour may exist between university students in different health professional specialities and in different universities. Such differences might be accentuated by international comparisons.

Cross-cultural differences in self-reporting behaviour may also exist between university students in Asia and those of Western countries. Previous research conducted among Asian nursing students (Smith et al., 2005; Smith, Sato, et al., 2003) indicates that the issue of Confucianism may be very important, as there may be a tendency for these students to under-report LBP symptoms. That is, out of respect for their teachers, students may be unwilling to report negative events. If so, self-assessed perceptions of pain (as determined by questionnaire surveys), may vary between different ethnic groups and will need to be investigated with more extensive, cross-cultural research. The development of a standardised LBP questionnaire for administration internationally to university students could be useful in this regard. Even so, it would still need to be tested and validated across a variety of countries and different cultures, as well as among different health professional student groups, such as occupational therapy, physiotherapy, nursing, medicine, and dentistry.

Using simple chi square analysis ( $\mathrm{P}$ for Trend), we noted that there were statistically significant differences in overall LBP prevalence rates by year of study in the occupational therapy course, with fourth-year students having the highest rates. This correlation also remained when evaluated in a combined regression model, which would have accounted for interactions between LBP and confounding demographic variables (such as increasing age with increasing year of study). Indeed, our logistic regression model also demonstrated that being a fourth-year student was a risk factor for LBP. Interestingly, these statistically significant correlations between LBP and year of study in the occupational therapy course were contrary to previous investigations of nursing students in Korea (Smith et al., 2005) and Japan (Smith, Sato et al., 2003), where no such relationships were found. In any case, fourth-year students may incur an increased LBP risk, compared to students in the other years of study, as a result of their occupational therapy practice placements. If this were so, it is possible that third-year students who are undertaking practical placements for the first time may be at even higher LBP risk, although we were unable to survey third-year students in this present study. It is also possible that as they progress through the course, occupational therapy students learn more about body pain and simply become more attuned to any LBP symptoms they may experience. On the other hand, the significantly higher percentage of fourth-year students whose LBP symptoms persisted longer than two days suggests the possibility of some genuine organic conditions, perhaps an exacerbation of pre-existing conditions, concepts that will need to be studied in future research projects. Nonetheless, these results have implications for health professional students entering the occupational therapy workforce, where job demands are likely to increase.

Although our study of LBP among occupational therapy students was strengthened by a high response rate and provided some interesting findings, further investigations may be helpful. In particular, longitudinal studies would help establish epidemiological patterns of LBP during the various years of the occupational therapy course and then after an occupational therapy student begins full-time employment. Retrospective studies may also be useful in elucidating any pre-existing conditions. Generalizability of the results are limited as this survey covered occupational therapy students from only one of the two occupational therapy schools in Queensland, Australia. It was also difficult to ascertain whether gender is a risk factor for LBP, as there was a relatively low proportion of male occupational therapy students in our study, which may have prevented us from revealing any existing LBP differences at a statistically significant level. 


\section{Conclusion}

Overall, our current study suggests that occupational therapy students in northern Queensland suffer considerably from LBP, perhaps even more so than other health professional student groups and some working populations. The high prevalence of LBP amongst first-year occupational therapy students raises concerns about the possibility of pre-existing conditions. In addition, the prevalence of LBP increased markedly by year of study in the program. Further investigations are required to elucidate the mechanisms and contributory factors for LBP among this particular student population.

\section{Acknowledgements}

We are grateful to all students who completed our questionnaire and to staff from the Discipline of Occupational Therapy, James Cook University, Townsville, for their organisational support. Thanks are also due to Dr. Frances Leggat for her assistance in data coding and entry.

\section{References}

Baron, S., Hales, T., \& Hurrell, J. (1996). Evaluation of symptom surveys for occupational musculoskeletal disorders. American Journal of Industrial Medicine, 29, 609-617.

Björkstén, M. G., Boquist, B., Talbäck, M., \& Edling, C. (1999). The validity of reported musculoskeletal problems. A study of questionnnaire answers in relation to diagnosed disorders and perception of pain. Applied Ergonomics, 30, 325-330.

Bland, J. M., \& Altman, D. G. (2000). The odds ratio. British Medical Journal, 320, 1468.

Coe, R. M., Miller, D. K., Wolff, M., Prendergast, J. M., \& Pepper, M. (1982). Attitudes and health promoting behavior of medical and law students. American Journal of Public Health, 72, 725-727.

Hamilton, A. G., Jacobs, K., \& Orsmond, G. (2005). The prevalence of computer-related musculoskeletal complaints in female college students. Work, 24, 387-394.

Holmström, E., \& Moritz, U. (1991). Low back pain Correspondence between questionnaire, interview and clinical examination. Scandinavian Journal of Rehabilitation Medicine, 23, 119-125.

Hupert, N., Amick, B. C., Fossel, A. H., Coley, C. M., Robertson, M. M., \& Katz, J. N. (2004). Upper extremity musculoskeletal symptoms and functional impairment associated with computer use among college students. Work, 23, 85-93.

Kamwendo, K. (2000). Adherence to healthy lifestyles: A comparison of occupational therapy students with nursing and physiotherapy students. Scandinavian Journal of Occupational Therapy, 7, 156-164.

Kuorinka, I., Jonsson, B., Kilbom, A., Vinterberg, H., BieringSørensen, F., Andersson, G. et al. (1987). Standardised Nordic questionnaires for the analysis of musculoskeletal symptoms. Applied Ergonomics, 18, 233-237.

Lagerström, M., Wenemark, M., Hagberg, M., Hjelm, E. W.,
\& The Moses Study Group. (1995). Occupational and individual factors related to musculoskeletal symptoms in five body regions among Swedish nursing personnel. International Archives of Occupational and Environmental Health, 68, 27-35.

Leggat, P. A., \& Smith, D. R. (2006). Musculoskeletal disorders self-reported by dentists in Queensland, Australia. Australian Dental Journal, 51, 324-327.

Najem, G. R., Passannante, M. R. C., \& Foster, J. D. (1995). Health risk factors and health promoting behavior of medical, dental and nursing students. Journal of Clinical Epidemiology, 48, 841-849.

National Occupational Health and Safety Commission [NOHSC]. (2002). National data set for compensationbased statistics, 2000-01 (NDS2). Retrieved October 5, 2006, from http://www.nohsc.gov.au/OHSInformation /NOSI/default.asp.

Occupational Therapy Australia. (2005). About occupational therapy. Retrieved November 7, 2005, from http://www. ausot.com.au/inner.asp?pageid $=85$.

Rising, D. W., Bennett, B. C., Hursh, K., \& Plesh, O. (2005). Reports of body pain in a dental student population. Journal of the American Dental Association, 136, 81-86.

Smith, D. R., Choe, M. A., Chae, Y. R., Jeong, J. S., Jeon, M. Y., \& An, G. J. (2005). Musculoskeletal symptoms among Korean nursing students. Contemporary Nurse, 19, 151160.

Smith, D. R., \& Leggat, P. A. (2004). Musculoskeletal disorders among rural Australian nursing students. Australian Journal of Rural Health, 12, 241-245.

Smith, D. R., \& Leggat, P. A. (2007). Prevalence and distribution of musculoskeletal complaints among medical students. Journal of Musculoskeletal Pain, 15(4), 39-46.

Smith, D. R., Leggat, P. A, Smyth, W., \& Wang, R.-S. (2003). Musculoskeletal disorders among female Australian nurses working in a unique tropical environment: Results from a pilot study. Ergonomics Australia, 17(3), 14-17.

Smith, D. R., Sato, M., Miyajima, T., Mizutani, T., \& Yamagata, Z. (2003). Musculoskeletal disorders selfreported by female nursing students in central Japan: A complete cross-sectional survey. International Journal of Nursing Studies, 40, 725-729.

Smith, D. R., Wei, N., Zhao, L., \& Wang, R. S. (2004). Musculoskeletal complaints and psychosocial risk factors among Chinese hospital nurses. Occupational Medicine, 54, 579-582.

SPSS, Inc. (2005). Statistical Package for the Social Sciences, Version 14.0.1. Chicago, IL: SPSS, Inc.

Trinkoff, A. M., Lipscomb, J. A., Geiger-Brown, J., \& Brady, B. (2002). Musculoskeletal problems of the neck, shoulder and back and functional consequences in nurses. American Journal of Industrial Medicine, 41, 170-178.

Woolf, A. D., \& Pfleger, B. (2003). Burden of major musculoskeletal conditions. Bulletin of the World Health Organization, 81, 646-656. 


\section{Authors}

Peter A. Leggat, DrPH, PhD, MD, is Professor and Head of School of Public Health, Tropical Medicine and Rehabilitation Sciences, James Cook University, Townsville, 4811 Queensland, Australia. Tel. +61-7-47816108. Fax. +61-747815254. E-Mail. Peter. Leggat@jcu.edu.au

Derek R. Smith, PhD, DrMedSc, is a Research Scientist, International Centre for Research Promotion and Informatics, National Institute of Occupational Safety and Health, Kawasaki, Japan 214-8585. He is also an Adjunct Senior Principal Research Fellow, School of Public Health, Tropical Medicine and Rehabilitation Sciences, James Cook University, Townsville, 4811 Queensland, Australia.

Michele J. Clark, BOccThy (Hons), PhD, is Professor and Head of Rehabilitation Sciences, School of Public Health, Tropical Medicine and Rehabilitation Sciences, James Cook University, Townsville, 4811 Queensland, Australia.

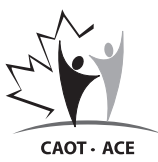

Copyright of articles published in the Canadian Journal of Occupational Therapy (COT) is held by the Canadian Association of Occupational Therapists. Permission must be obtained in writing from CAOT to photocopy, reprint, reproduce (in print or electronic format) any material published in COOT. There is a per page, per table or figure charge for commercial use. When referencing this article, please use APA style, citing both the date retrieved from our web site and the URL. For more information, please contact: copyright@caot.ca. 